Eddy Currents in the NSLS Vacuum Chamber

Samuel Krinsky

INFORMAL REPORT:

B R O O K H A VEN NATIONAL L A B ORA TOR Y

U P T O N, N E W Y O R K 11973 
This report was prepared as an account of work sponsored by the United.States Government. Neither the United States nor the. United States Department of Energy, nor any of their employees, nor any of their contractors, subcontractors, or their employees, makes any warranty, express or implied or assumes any legal liability or responsibility for the accuracy, completeness or usefulness of any information, apparatus, product or process disclosed or represents that its use would not infringe privately owned rights. 


\section{Eddy Currents in the NSLS Vacuum Chamber ${ }^{*}$ \\ Samue 1 Krinsky}

Brookhaven National Laboratory, Upton, New York 11973

As the applied magnetic fields are increased during acceleration, eddy currents are induced in the vacuum chamber. These result in magnetic field perturbations which we shall estimate for the Booster and X-Ray Rings. Our calculation follows that of Asner ${ }^{(1)}$, in particular, we use image currents to satisfy the boundary conditions imposed by the iron poles of the magnets. The strength of the magnetic field perturbations is roughly three times greater with the iron poles present than absent.

We shall use mks units in this note. Writing the applied magnetic field as

$$
\mathrm{B}=\nabla \times \mathrm{A},
$$

the eddy current density is

$$
j_{e}=-\sigma \frac{\partial A}{\partial t}+c(t)
$$

where $\sigma$ is the conductivity in $\Omega^{-1} \mathrm{~m}^{-1}$, and $c(t)$ does not depend on the spatial coordinates and is determined by the condition that the net eddy current be zero. The magnetic field perturbation is $\Delta B=\nabla \times A_{e}$, where

$$
A_{e}(x, y)=-\frac{\mu}{4 \pi} \iint d x^{\prime} d y^{\prime} j_{e}\left(x^{\prime}, y^{\prime}\right) \ln \left[\left(x-x^{\prime}\right)^{2}+\left(y-y^{\prime}\right)^{2}\right]
$$

Introducing the skin depth $\delta_{\mathrm{s}}^{-2}=\frac{1}{2} \sigma_{\mu}(\mathrm{dB} / \mathrm{d} t) / \mathrm{B}$,

the thickness of the vacuum chamber wall $\delta$, and the effective radius $R$ equal to the circumference of the chamber divided by $2 \pi$, dimensional arguments indicate

$$
\Delta \mathrm{B} / \mathrm{B} \sim-\delta \mathrm{R} / \delta_{\mathrm{S}}^{2}
$$

For a 2n-pole field applied to a circular chamber in the absence of $\operatorname{iron}^{(2)}$,

$$
\Delta \mathrm{B} / \mathrm{B}=-\mathrm{n}^{-1} \delta \mathrm{R} / \delta_{\mathrm{S}}^{2}
$$

$*$

Research supported by the Division of Basic Energy Sciences, Department of Energy, under Contract No. EY-76-C-02-0016. 
and for a dipole field applied to two parallel plates ${ }^{(1)}$ of width $2 a$, separated by $2 b$,

$$
\Delta \mathrm{B}(\mathrm{x}, 0) / \mathrm{B}=-2\left(\delta \mathrm{R} / \delta_{\mathrm{s}}^{2}\right)\left[1-\frac{\mathrm{b}}{\mathrm{a}} \tan ^{-1} \frac{\mathrm{a}}{\mathrm{b}}-\frac{\mathrm{a}^{2} \mathrm{x}^{2}}{\left(\mathrm{a}^{2}+\mathrm{b}^{2}\right)^{2}}+0\left(\mathrm{x}^{4}\right)\right],
$$

where $R=2 a / \pi$.

Booster Dipole Booster Quad X-Ray Dipole X-Ray Quad

$\begin{array}{ccccc}\sigma & 8.3 \times 10^{5} \Omega^{-1} \mathrm{~m}^{-1} & 8.3 \times 10^{5} & 3.5 \times 10^{7} & 3.5 \times 10^{7} \\ \delta & 0.75 \mathrm{~mm} & 2.37 & 4.0 & 4.0 \\ \mathrm{R} & 43 \mathrm{~mm} & 43 & 65 & 41 \\ \mathrm{~B} \frac{\mathrm{dt}}{\mathrm{dB}} & 0.4 \mathrm{sec} & 0.4 & 60 & 60 \\ \delta_{\mathrm{s}} & 870 \mathrm{~mm} & 870 & 1600 & 1600 \\ \delta \mathrm{R} / \delta_{\mathrm{s}}^{2} & 0.4 \times 10^{-4} & 1.2 \times 10^{-4} & 1 \times 10^{-4} & 0.6 \times 10^{-4}\end{array}$

We see that a $60 \mathrm{sec}$ rise time in the aluminum chamber of the $\mathrm{X}$-ray ring results in comparable field perturbations as produced by a 0.4 sec rise time in the Inconel chamber of the booster. The results of numerical calculations including the detailed geometry of the vacuum chamber and the boundary conditions due to iron poles are given in Figures 1 thru 5 .

Booster Quadrupole (Fig. 1) and X-ray Quadrupole (Fig. 2)

The variation of the gradient across the aperture is less than $0.1 \%$, and for $x \leq 2.0 \mathrm{~cm}$ the variation is predominantly octupole. This gradient variation should not be a problem. The horizontal asymetry of the X-ray vacuum chamber in the quadrupoles, due to the water cooling channels, results in a small dipole and sextupole component of the field perturbation. Booster Dipole (Figs. 3 and 4 )

In Fig. 3 we consider the regular booster chamber, and in Fig. 4 the booster chamber with the vacuum pump takeoff port.

$$
\begin{aligned}
& \text { tune shift: } \Delta \nu_{y}=-\frac{N}{4 \pi} \frac{I \Delta B^{\prime}}{B \rho} \bar{\beta}_{y} \\
& \text { chromaticity change: } \Delta \xi_{y}=-\frac{N}{4 \pi} \frac{I \Delta B^{\prime \prime}}{B \rho} \bar{\beta}_{y} \bar{\eta}
\end{aligned}
$$


For the booster $N=8, B p=3.33 \mathrm{KG}-\mathrm{m}(E=100 \mathrm{MeV}), \bar{\beta}_{\mathrm{y}}=4.5 \mathrm{~m}, \bar{\eta}=0.3 \mathrm{~m}$. The regular chamber has $\mathrm{L}=1.2 \mathrm{~m}$,

$$
\begin{aligned}
& \frac{L \Delta B^{\prime}}{B p}=5.7 \times 10^{-4} \mathrm{~m}^{-1}, \frac{L \Delta B^{\prime \prime}}{B p}=0.25 \mathrm{~m}^{-2}, \\
& \Delta \nu_{y}=-1.6 \times 10^{-3}, \\
& \Delta \xi_{y}=-0.2,
\end{aligned}
$$

and the chamber with pump has $L=0.3 \mathrm{~m}$,

$$
\begin{aligned}
& \frac{I \Delta B^{\prime}}{B p}=4.7 \times 10^{-3} m^{-1}, \frac{L \Delta B^{\prime \prime}}{B \rho}=-0.073 m^{-2}, \\
& \Delta \nu_{y}=-0.013 \\
& \Delta \xi_{y}=0.06 .
\end{aligned}
$$

In these calculations we have included the quadrupole and sextupole component of the applied magnetic field in the Booster bending magnet.

\section{X-Ray Dipole (Fig. 5)}

$$
\begin{aligned}
N=16, B \rho & =23.3 \mathrm{KG}-\mathrm{m}(E=700 \mathrm{MeV}), \bar{\beta}_{\mathrm{y}}=16 \mathrm{~m}, \bar{\eta}=0.25 \mathrm{~m}, \\
\frac{I \Delta B^{\prime}}{B \rho} & =1.9 \times 10^{-3} \mathrm{~m}^{-1}, \frac{I \Delta B^{\prime \prime}}{B \rho}=0.088 \mathrm{~m}^{-2}, \\
\Delta \nu_{y} & =-0.04 \\
\Delta \bar{s}_{y} & =-0.45
\end{aligned}
$$

The relatively large gradient error is due to the asymmetry in the vacuum chamber introduced by the distributed pump.

\section{Slow Bump in the VUV-Ring}

Consider a 4 mrad kick applied in 0.1 sec by a back leg winding on the bending magnet. This corresponds to a $62 \mathrm{G}$ field change in 0.1 sec or

$$
\frac{\mathrm{dB}}{\mathrm{dt}}=620 \mathrm{G} / \mathrm{sec} \text {. }
$$


Scaling our previous result for the $X$-ray bending magnet by $620 / 146$, we obtain the magnetic field perturbation due to eddy currents,

$$
\Delta B=-19.6 \mathrm{G}+(70 \mathrm{G} / \mathrm{m}) \mathrm{x}+\left(1625 \mathrm{G} / \mathrm{m}^{2}\right) \mathrm{x}^{2}+
$$

We see that this is a significant effect. 


\section{References}

1. A. Asner, Calculation of Eddy Current Effects in the Vacuum Chamber of the Booster Synchrotron Quadrupole and Bending Magnets, MPS/Int. MA 67-11.

2. J. C. Herrera, Eddy Current Effects in the ISA Vaccum Chamber, BNL 19513. 
Figure 1. BODSTER QUADRUPOCE

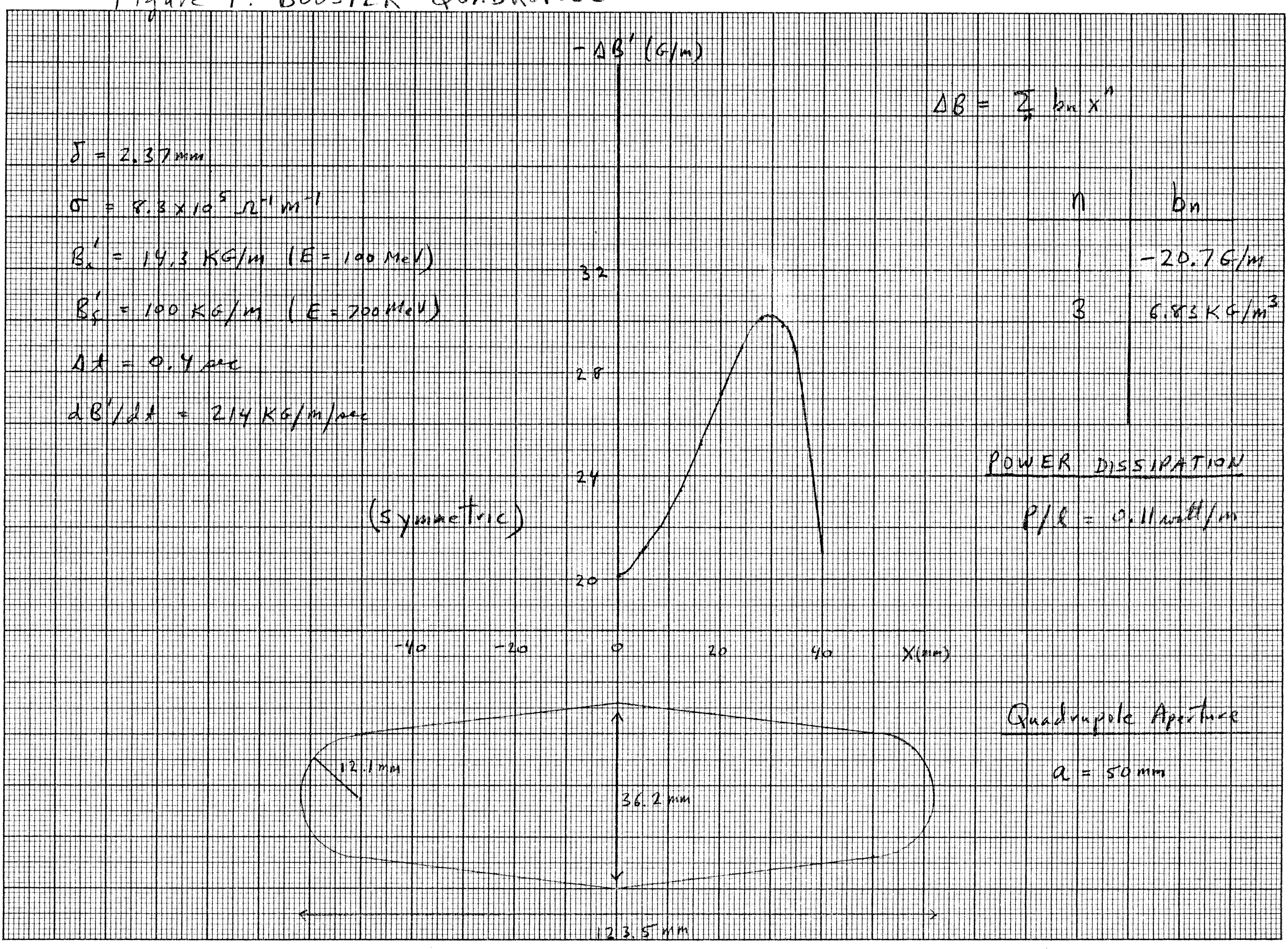


Figure 2. X-RAY QUADRUPOLE

\begin{tabular}{|c|c|c|c|}
\hline &
\end{tabular}




\section{Figure 3. BOOSTER DIPOLE}

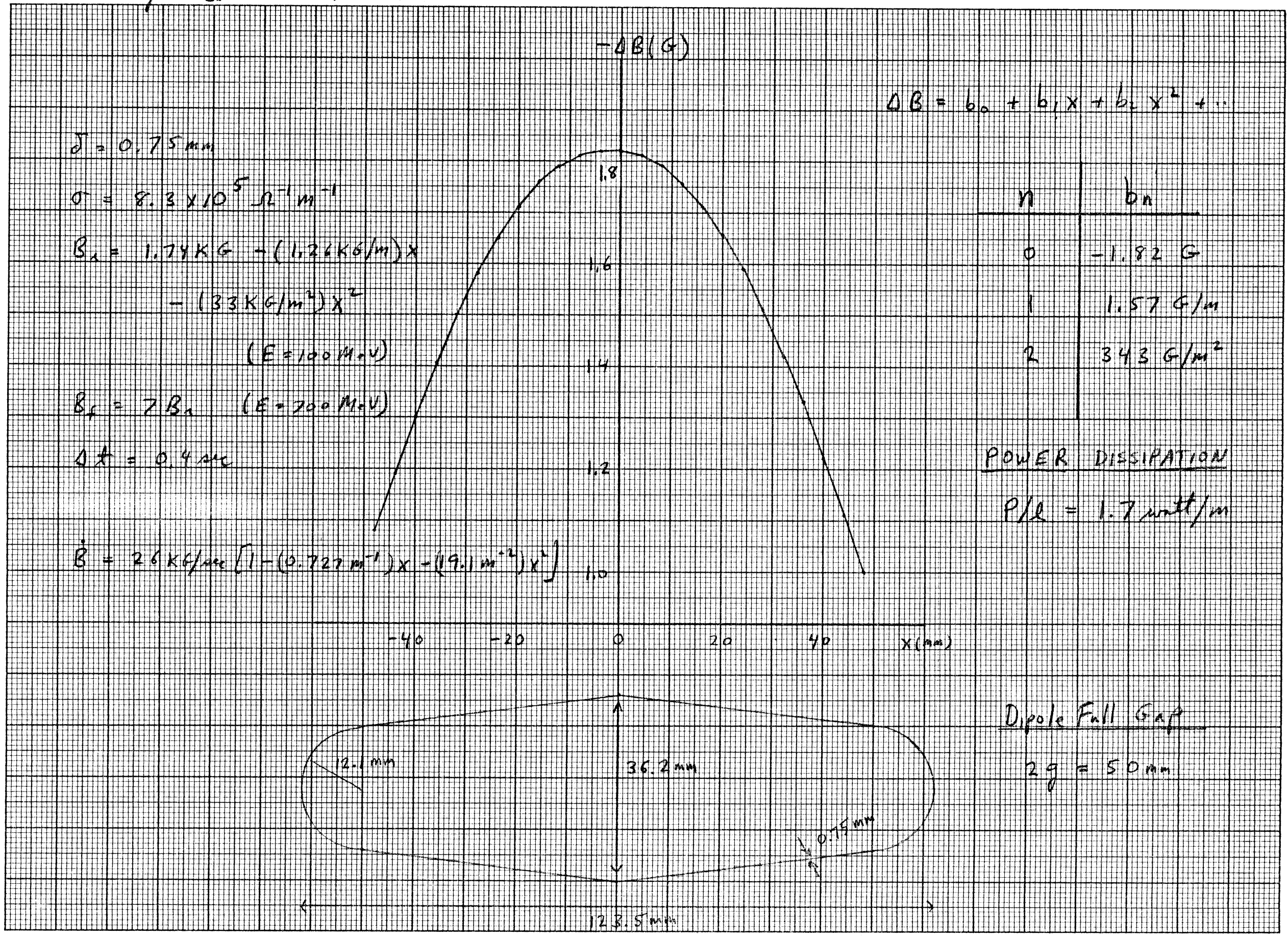


Figure 4. BOOSTER DIPOLE (WITH VACUUM PUMP TAKEOFF PORT)

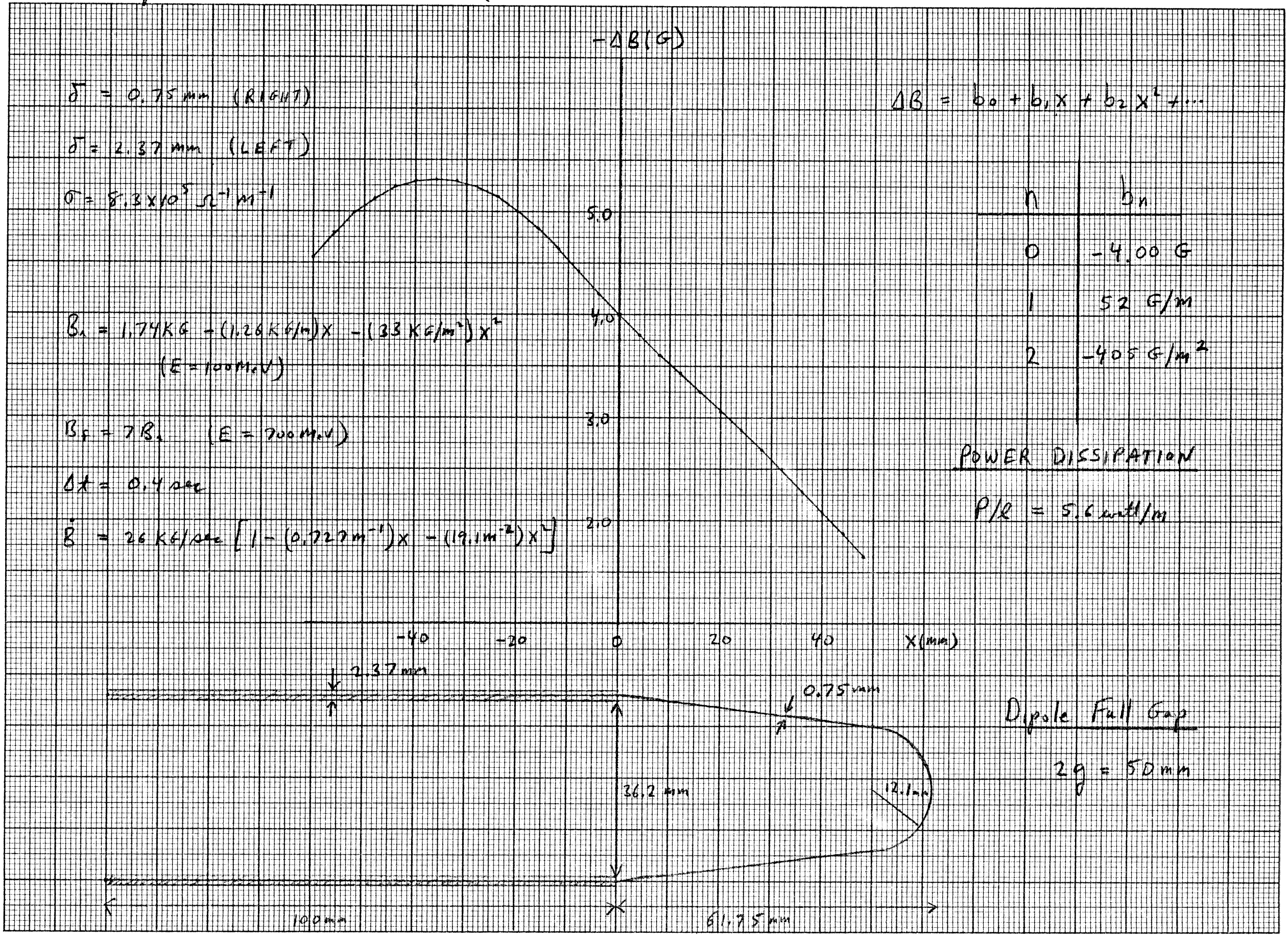




\section{Figure 5. XRAY RING DIPOSE}

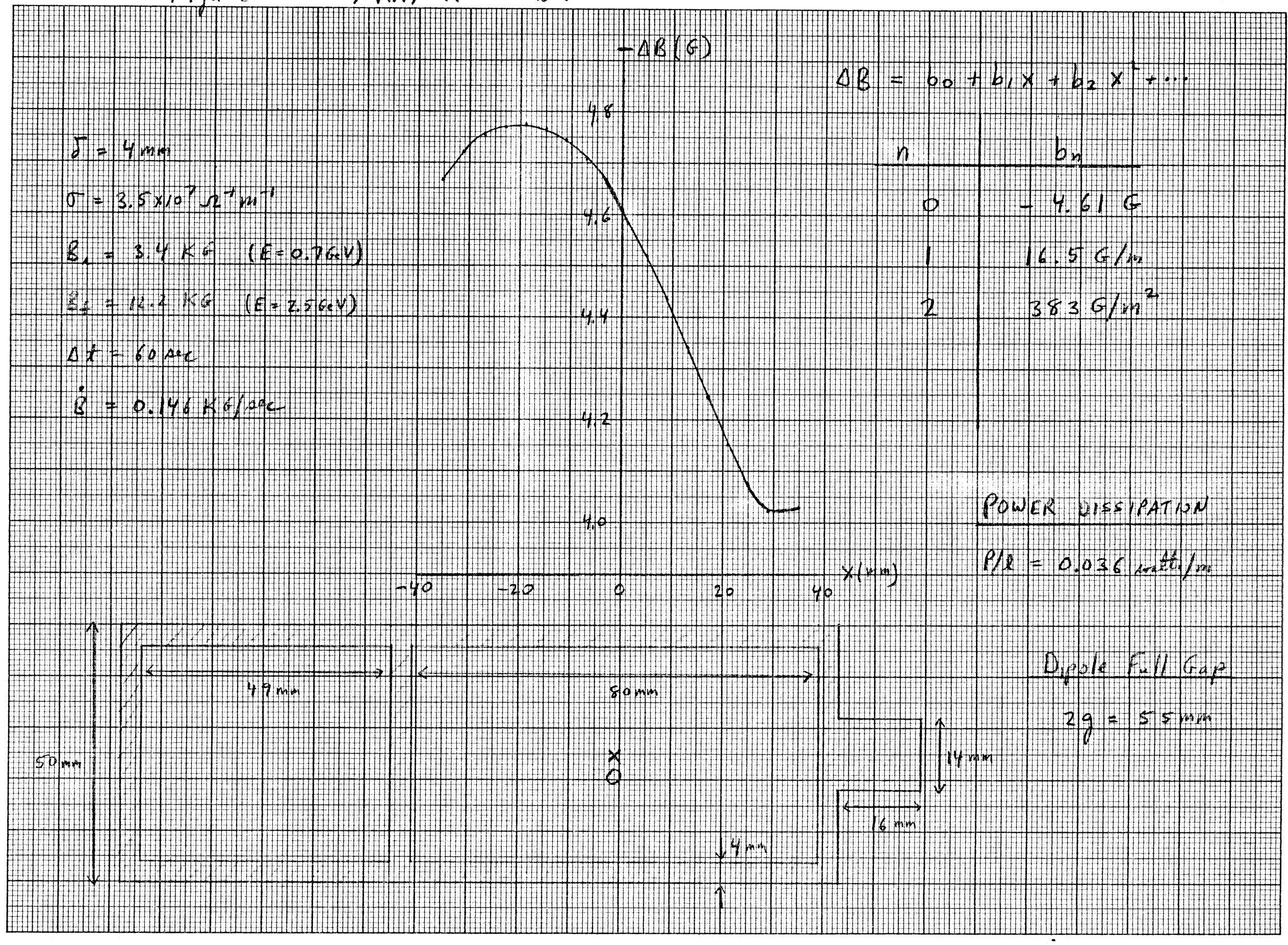


